J. Lake Sci. (湖泊科学), 2015, 27(6): 1151-1158

DOI 10. 18307/2015.0621

(C) 2015 by Journal of Lake Sciences

\title{
不同条件下乌梁素海污染物在冰-水体系中分布规律的模拟”
}

\author{
吕宏洲, 李畅游*, 史小红, 赵胜男, 杨 芳, 吴用, 宋 爽 \\ (内蒙古农业大学水利与土木建筑工程学院, 呼和浩特 010018 )
}

\begin{abstract}
摘 要: 为探讨单一因素 (如浓度、温度、酸碱度) 对冰封期乌梁素海中营养盐和盐分 (总氮、总磷、 $\mathrm{Na}^{+}$和 $\mathrm{Cl}^{-}$) 迁移的影 响, 对不同条件下各物质水样进行室内单向结冰模拟, 分析总结物质在冰层和冰下水层中的分布特征, 并用分配系数 $(K)$ 来表征. 结果表明: 冰体中物质浓度随水样初始浓度 $\left(C_{0}\right)$ 的增大而增大, 随结冰温度的升高而减小; 各物质在冰体中的浓 度分布表现为顶层 < 中层 <底层. 总氮、总磷的分配系数 $K$ 随 $C_{0}$ 的增大呈递减趋势, $\mathrm{Na}^{+}$和 $\mathrm{Cl}^{-}$的 $K$ 值随 $C_{0}$ 的增大呈递 增趋势; 对各条件下的 $K$ 值进行假设检验, 结果为: 水样中物质初始浓度和结冰温度显著影响其在冰一水体系中的分布; 同一温度下, $C_{0}$ 较小时, 酸碱度显著影响各物质在冰一水体系中的分布, $C_{0}$ 较大时, 酸碱度显著影响 $\mathrm{Na}^{+}$和 $\mathrm{Cl}^{-}$在冰一水体 系中的分布, 但对总氮、总磷浓度分布的影响不显著. 可见, 在不同环境因素下, 各物质在冰一水体系中表现出不同的分布 特征,对此进行模拟可为寒区湖泊污染物迁移和生物地球化学循环的研究提供一定的参考.
\end{abstract}

关键词: 单向结冰模拟; 冰水双介质;物质迁移;分配系数;乌梁素海

\section{Pollutant distribution under different conditions in Lake Ulansuhai ice-water system}

\author{
LÜ Hongzhou, LI Changyou, SHI Xiaohong, ZHAO Shengnan, YANG Fang, WU Yong \& SONG Shuang \\ (College of Water Conservancy and Civil Engineering, Inner Mongolia Agricultural University, Huhhot 010018, P. R. China)
}

\begin{abstract}
Laboratory unidirectional freezing experiments were performed to investigate the migration of nutrients( TN, TP) and salinity $\left(\mathrm{Na}^{+}, \mathrm{Cl}^{-}\right)$in Lake Ulansuhai water during ice season, and difference among single factors, including initial concentration, freezing temperature and $\mathrm{pH}$ were tested. The distributions of $\mathrm{TN}, \mathrm{TP}, \mathrm{Na}^{+}, \mathrm{Cl}^{-}$in simulation ice cores were studied and partition coefficients between the ice and the unfrozen liquid were determined. The results showed that concentrations in ice increased with enhancing initial concentration and decreased with enhancing freezing temperature. The concentration in various segments of the ice phase was in the order of : top $<$ middle $<$ bottom. The higher initial concentration, the lower partition coefficient $K$ of TN and TP, but higher $\mathrm{K}_{\text {of }} \mathrm{Na}^{+}$and $\mathrm{Cl}^{-}$. At the significant level of 0.05 , we found: different initial concentration and freezing temperature can significant affect the distribution of TN, TP, $\mathrm{Na}^{+}$and $\mathrm{Cl}^{-}$. At different $\mathrm{pH}$ conditions, their distribution varies in lower initial concentration, but no significant change is found in higher initial concentration of TN and TP. Results indicated that transport processes of contaminants were greatly affected by its physical properties and the freezing environment factors.
\end{abstract}

Keywords: Unidirectional freezing experiment; ice-water double phase medium; matter migration; partition coefficient; Lake Ulansuhai

溶液结冰过程会将溶质排人到尚未冻结的水中. 这一现象在不同领域被广泛研究. 在国外, 冷冻浓缩多 应用于食品加工领域, 如对咖啡汁 ${ }^{[1]}$ 、果汁 ${ }^{[2-3]}$ 等进行浓缩, 以及对低温储藏过程结冰引起食品结构、 $\mathrm{pH}$ 值、 蛋白质等质量变化的研究; 在环境污染方面, 用于海水的脱盐淡化 ${ }^{[4]}$. 研究过程中水体结晶方式有 3 种: 低 温条件下将晶体与母液不断分离的悬浮结晶法; 只在浸人恒温冷水浴中的液体表面形成片状冰晶的渐进冷 冻法; 坚直和径向方向同时进行的常态冻结法. 在冶炼厂用结冰的方式消除废水中的污染物, 同时, 模拟冷 冻过程中结冰速率、搅拌速度等因素对污水处理效率的影响 ${ }^{[5-6]}$. 在国内, 通过测量极地冰芯的 $\mathrm{pH}$ 值和电导

* 国家自然科学基金项目 $(51339002,51269016,51269017,51169017)$ 资助. 2014-12-18 收稿; 2015-04-09 收修改 稿. 吕宏洲(1989 ), 女, 硕士研究生;E-mail:lhz_imau@ aliyun. com.

** 通信作者;E-mail:nndlichangyou@ 163. com. 
率来反演空气污染的历史 ${ }^{[7]}$; 于涛等 ${ }^{[8]}$ 应用两级冷冻分离法通过处理空间站尿液的实验提出了制备高纯度 冰晶的方法; 张岩等 ${ }^{[9]}$ 从固液相平衡理论、结晶学理论和热力学理论 3 方面解释冷冻浓缩效应的机理并分 析其对水处理的意义; 张晓庆等 ${ }^{[10]}$ 将冷冻技术应用于环渤海盐碱地区生活污水的处理中, 并讨论了温度、机 械搅拌等因素对生活污水中污染物去除率的影响; 李志军等 ${ }^{[11]}$ 对不同浓度流动水体冻融过程中硝基苯在冰 水体系的分配进行室内模拟研究, 提出融冰过程中硝基苯在冰体内不发生迁移. 值得注意的是, 目前的研究 多集中在结冰过程中溶质由冰相迁移至冰下水相这一过程的应用, 而对自然湖泊中由于冰封而引起的污染 物迁移的研究还很有限.

水结冰过程中溶质的重新分配对湖泊污染物迁移转化及治理有重要的意义. 吴攀等 ${ }^{[12]}$ 的模拟研究表 明, 冬、春季节由于水温和营养盐的不同会对太湖藻类生长和群落交替产生不可忽视的作用. 北方地区冰封 期长达 4 6 个月, 湖水冻结过程污染物质在冰一水介质中的迁移对湖泊生态系统具有重要的影响. 黄继国 等 ${ }^{[13]}$ 研究冰封期长春市南湖水中营养盐、浮游植物、叶绿素 ${ }^{[14]}$ 的分布特征, 表明冰封期污染物质的分布有 着不同于非冰封期的特殊性. 乌梁素海是河套灌区典型的富营养化湖泊, 水体的水化学类型为 $[\mathrm{Cl}] \mathrm{NaW}$ 型 ${ }^{[15]}$, 电导率范围为 $0.07 \sim 12.32 \mathrm{mS} / \mathrm{cm}$, 均值为 $4.12 \mathrm{mS} / \mathrm{cm}$, 可见湖泊盐化程度较高 ${ }^{[16]}$. 本文在总结前人 经验的基础上, 设计了单向湖泊结冰模拟器, 通过室内模拟试验, 选取湖泊富营养化主要污染物总氮、总磷 和乌梁素海湖水中主要水化学离子 $\mathrm{Na}^{+}$和 $\mathrm{Cl}^{-[15]}$ 为研究对象, 考察不同浓度、温度、酸碱度条件下各物质的 单向结冰过程, 并用分配系数定量说明冰冻作用对于湖泊污染物在环境中迁移及分布的影响, 以期为冰封 期湖泊化学环境变化的研究及富营养化治理提供基础数据和科学依据.

\section{1 材料与方法}

\section{1 结冰模拟装置}

实验采用单向湖泊结冰模拟器模拟 (图 1). 该仪器为空心圆柱体即大小两圆柱体嵌套, 小柱体敞口, 用 于放置实验水样, 大、小柱体之间包括底部填充保温材料, 确保冷能量只从小柱体上部敞口处向下传递, 以 此模拟湖泊在自然条件下自上而下结冰的过程. 小柱体可以独立取出, 方便清洗以及结冰后冰柱的脱出, 并 设可活动底, 用来释放结冰过程中由于体积膨胀而产生的压力, 这样有利于对实验仪器的保护, 而且更接近 自然状态下湖泊环境的压力条件. 模拟结冰过程实验在低温冷库中进行, 整个实验装置运行良好.

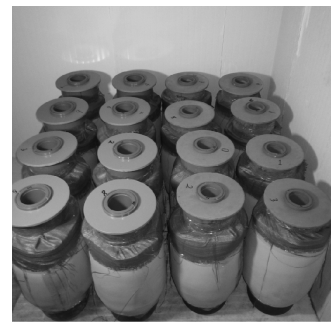

结冰模拟器

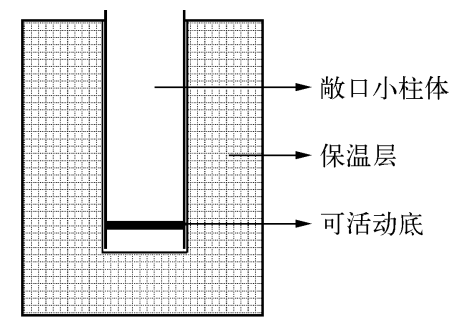

结冰模拟器内部结构示意

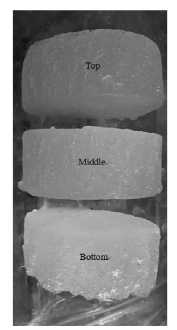

$-25^{\circ} \mathrm{C}$ 得到的 $\mathrm{NaCl}$ 冰芯(经切分)

图 1 单向湖泊结冰模拟装置及模拟冰芯

Fig. 1 Unidirectional lake water freezing stimulated device and the ice core

\section{2 实验设计}

实验模拟冰封期湖水中总氮 $(\mathrm{TN})$ 、总磷 $(\mathrm{TP}) 、 \mathrm{Na}^{+}$和 $\mathrm{Cl}^{-}$在冰水介质的迁移过程, 分别在 3 种条件下进 行:不同浓度 $($ 表 1$)$ 、不同温度 $\left(-25,-15^{\circ} \mathrm{C}\right)$ 、不同 $\mathrm{pH}$ 值.

实验水样配制: 为了分析浓度、温度、 $\mathrm{pH}$ 值对物质在湖泊环境中迁移的影响而不受复杂湖泊环境系统 其他因素的干扰, 在超纯水中加人各浓度标准物质 (表 1 ) 作为中性条件水样 (纯水机厂家及型号: thermofisher purlab flex). 在超纯水中加人 $\mathrm{HCl}(1 \mathrm{~mol} / \mathrm{L})$ 调节其 $\mathrm{pH}$ 值为 5 后, 加人各浓度标准物质, 作为酸性水 样; 在超纯水中加人 $\mathrm{NaOH}(1 \mathrm{~mol} / \mathrm{L})$ 调节其 $\mathrm{pH}$ 值为 11 , 加人各浓度标准物质, 作为碱性水样 $(\mathrm{NaCl}$ 水样的 $\mathrm{pH}$ 值由 $\mathrm{HNO}_{3}$ 和 $\mathrm{KOH}$ 调节). 根据地表水环境质量标准 $(\mathrm{GB} 3838-2002)$ ), 乌梁素海全湖呈 $\mathrm{V}$ 类水质 ${ }^{[17]}$. 
实验水样的初始浓度设置为 $\mathrm{V}$ 类水中 $\mathrm{TN} 、 \mathrm{TP}$ 的标准限值以及集中式生活饮用 水地表水源地补充项目中氯化物的标准 限值作为 $C_{1}$ 值, 并在 $C_{1}$ 的基础上加倍, 分 别作为水样初始浓度 $C_{2} 、 C_{3} 、 C_{4}$.

实验方法:将配置好的水样 $(2 \mathrm{~L})$ 倒 人模拟器后, 置于冷库中, 使得结冰体积 为总体积的 $1 / 2$ 左右取出, 符合乌梁素海 冰封期冰水体积比 $1 / 3 \sim 1 / 2^{[18]}$ 的比例.
表 1 实验用标准物质的浓度

Tab. 1 Concentration of the standard materials used in the experiment

\begin{tabular}{lcccc}
\hline 标准物质(样品编号 $)$ & $\begin{array}{c}C_{1} / \\
(\mathrm{mg} / \mathrm{L})\end{array}$ & $\begin{array}{c}C_{2} / \\
(\mathrm{mg} / \mathrm{L})\end{array}$ & $\begin{array}{c}C_{3} / \\
(\mathrm{mg} / \mathrm{L})\end{array}$ & $\begin{array}{c}C_{4} / \\
(\mathrm{mg} / \mathrm{L})\end{array}$ \\
\hline $\mathrm{TN}(\mathrm{GNM}-\mathrm{SNO3N-001b-2013)})$ & 2 & 5 & 10 & - \\
$\mathrm{TP}(\mathrm{GSB04-1741-2004)}$ & 0.4 & 4 & 10 & - \\
$\mathrm{NaCl}$ & 250 & 1000 & 5000 & 10000 \\
\hline
\end{tabular}

分别收集冰柱、冰下水, 测量记录冰柱长度, 并等长度切分为 3 段 (如图 1 ), 融化后待测. 每组处理做 3 个 平行.

\section{3 实验项目}

分析 $-25 、-15^{\circ} \mathrm{C}$ 下, 不同浓度 $\mathrm{TN} 、 \mathrm{TP} 、 \mathrm{Na}^{+}$和 $\mathrm{Cl}^{-}$在各冰层和冰下水体中的浓度; $-25^{\circ} \mathrm{C}, \mathrm{pH}$ 值为 $5 、 7 、$ 11 时, 不同浓度 $\mathrm{TN} 、 \mathrm{TP} 、 \mathrm{Na}^{+}$和 $\mathrm{Cl}^{-}$在各冰层和冰下水体中的浓度. 实验依据《水和废水监测分析方法》 ${ }^{[19]}$, $\mathrm{TN}$ 浓度采用碱性过硫酸钾消解- 紫外分光光度法测定, TP 浓度采用钿酸铵分光光度法进行测定 ( 分光光度 计型号: Hitachi UH5300), 运用离子色谱法分别测定 $\mathrm{Na}^{+}$和 $\mathrm{Cl}^{-}$的浓度 (离子色谱仪型号:Dionex ICS-1100). 统计分析在 SPSS 17.0 软件中进行, 采用 Origin 8.0 软件进行制图.

\section{2 结果与分析}

将冰柱顶端与冷源接触段作为顶层、底端与冰下水接触段作为底层、中间层作为中层. 测得各段 TN、 $\mathrm{TP} 、 \mathrm{Na}^{+}$和 $\mathrm{Cl}^{-}$的浓度值来说明其在冰相中的分布. 测得冰下水体的浓度, 将分配系数定义为:

$$
K=C_{\mathrm{s}} / C_{\mathrm{L}}
$$

式中, $C_{\mathrm{s}}$ 为冰中物质的浓度 (由于本文将冰柱等体积切分为三段冰, $C_{\mathrm{s}}$ 用三段冰的平均浓度表示), $C_{\mathrm{L}}$ 为冰下 水体中物质的浓度. 计算分配系数来表征不同物质在水体结冰过程中的排出效应.

\section{1 浓度、温度、pH 值对 TN、TP 的影响}

实验共设置 3 个初始浓度 $\left(C_{1} 、 C_{2} 、 C_{3}\right)$ 对 TN、TP 浓度进行结冰模拟.

2.1.1 浓度、温度对 TN 浓度在冰体一水体中分布的影响 不同浓度 $\mathrm{TN}$ 在 $-25 、-15^{\circ} \mathrm{C}$ 时在冰相各层的分 布, 折线表示分配系数 $K$ 的变化趋势 (图 2). 同一温度下随初始 TN 浓度 $\left(C_{0}\right)$ 的增加, 结冰后测得各冰层中 $\mathrm{TN}$ 浓度都有所增加. 由于溶液浓度增加, 其粘度增加, 扩散系数减小 ${ }^{[20]}$ 导致二次成核, 微小的粒状冰晶形 成, 冰晶表面积增加从而更多溶质留在冰中 ${ }^{[21]}$. 冰体 $\mathrm{TN}$ 浓度均表现为顶层 < 中层 <底层, 这一结果与乌梁 素海冰封期取得湖水冰芯后测得不同层 TN 浓度随冰厚度增加而增加 ${ }^{[22]}$ 的趋势一致, 说明本实验较接近乌 梁素海冰封期的实际情况.

同一浓度下, $-25^{\circ} \mathrm{C}$ 各冰层中 $\mathrm{TN}$ 浓度均大于 $-15^{\circ} \mathrm{C}$ 时相应冰层的浓度. 由于结冰温度较高时冰晶为柱 状, 冰水界面水平; 而结冰温度较低时, 冰晶生长为树枝状, 表面积扩大, 促进冰晶形成的同时, 捕获更多的 杂质 ${ }^{[21,23-24]}$,所以在相对较高温度下, 结冰对物质的排出作用越大.

用 $C_{\mathrm{L}} / C_{0}$ 表示冰下水体中 $\mathrm{TN}$ 浓度和结冰前水体 $\mathrm{TN}$ 浓度的比值, 则初始浓度分别为 $C_{1} 、 C_{2} 、 C_{3}$ 时: $-25^{\circ} \mathrm{C}$ 结冰, $C_{\mathrm{L}} / C_{0}$ 分别为 $1.63 、 1.75 、 1.83 ;-15^{\circ} \mathrm{C}$ 结冰, $C_{\mathrm{L}} / C_{0}$ 分别为 $1.71 、 1.78 、 1.87$. 冰体与冰下水体中 $\mathrm{TN}$ 浓度之和略小于初始溶液 TN 浓度, 主要由于结冰过程中冰体积有所损失, 但对趋势分析结果没有影响. 乌梁素海野外实测的不同深度冰下水 TN 浓度与结冰前水体浓度比在 $1.00 \sim 1.30$ 之间 ${ }^{[22]}$, 由于湖水中其他 物质的存在, 使得水样中总物质浓度较大, 所以结冰过程中留在冰体中的物质浓度增大, 从而测得的 $C_{\mathrm{L}} / C_{0}$ 值均比本实验小.

$\mathrm{TN}$ 水样初始浓度 $\geqslant$ 地表水质标准 $\mathrm{V}$ 类标准限值 $(2.0 \mathrm{mg} / \mathrm{L})$ 时: 在 $-25 、-15^{\circ} \mathrm{C}$ 结冰, 冰体中 $\mathrm{TN}$ 的平均 浓度均小于 II 类标准限值 $(0.5 \mathrm{mg} / \mathrm{L})$, 说明当乌梁素海未进人冰封期之前, 初始水样浓度只适用于农业用 
水及景观用水时, 经过冻结作用, 冰体中水质满足集中式生活饮用水地表水源地一级保护区, 鱼虾类产卵场 等水质要求,可见结冰对湖泊水体中 TN 具有净化作用.

$K$ 值随初始溶液浓度的增大而递减, 初始溶液浓度 $\left(C_{0}\right)$ 越大, 冰相中的 $\mathrm{TN}$ 浓度 $\left(C_{\mathrm{S}}\right)$ 越大, 但由于冰体 中 $\mathrm{TN}$ 浓度相比于整个冰水系统较小, 冰体中 $\mathrm{TN}$ 浓度的增加量远小于冰下水的增加量, 造成 $K$ 值减小的趋 势 (图 2). 相同浓度下, $-25^{\circ} \mathrm{C}$ 时 $K$ 值明显大于 $-15^{\circ} \mathrm{C}$ 时的 $K$ 值, 说明低温缓慢结冰有助于物质从冰相排出 到冰下水相. 运用单因素方差分析 (ANOVA, $\alpha=0.05$ ) 可得: 结冰过程中初始溶液浓度为 $C_{1} 、 C_{2} 、 C_{3}$ 时 $\mathrm{TN}$ 水 样得到的 $K$ 值差异显著 $(P=0 、 0 、 0.016<0.05)$, 相同浓度下分别运用独立样本 $t$ 检验, 得出冻结温度为 $-25 、-15^{\circ} \mathrm{C}$ 时对 $\mathrm{TN}$ 水样的 $K$ 值差异显著 $(P=0.001 、 0.002 、 0.022<0.05)$, 说明不同浓度、不同温度对 $\mathrm{TN}$ 在冰体一水体中分布的影响在统计学上有意义, 即冰封期 $\mathrm{TN}$ 在冰一水介质中的迁移受湖水中 $\mathrm{TN}$ 浓度和环境 温度的影响.

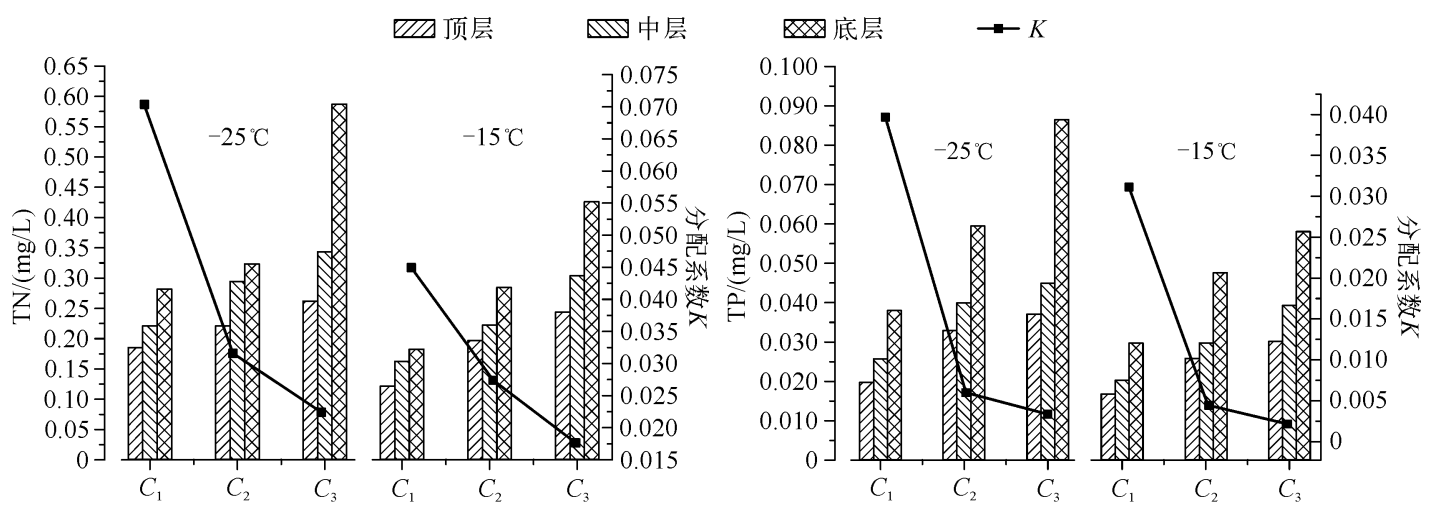

图 2 不同浓度、温度下 $\mathrm{TN} 、 \mathrm{TP}$ 浓度在冰体一水体中的分布

Fig. 2 Distribution of TN and TP concentrations in the water and ice systems under different initial concentrations and freezing temperatures

2.1 .2 浓度、温度对 TP 浓度在冰体一水体中分布的影响 $\mathrm{TP}$ 浓度(图 2) 在冰体中的分布情况与 TN 浓度基 本一致: 随初始浓度 $C_{0}$ 的增加, 冰体中的浓度增大; 随结冰温度的升高, 冰体中的浓度减小; 各冰层浓度均表 现为顶层 <中层 <底层. 用 $C_{\mathrm{L}} / C_{0}$ 表示冰下水体中 $\mathrm{TP}$ 浓度和结冰前水体 $\mathrm{TP}$ 浓度之比, 则浓度分别为 $C_{1}$ 、 $C_{2} 、 C_{3}$ 时: $-25^{\circ} \mathrm{C}$ 结冰, $C_{\mathrm{L}} / C_{0}$ 分别为 $1.74 、 1.81 、 1.92 ;-15^{\circ} \mathrm{C}$ 结冰, $C_{\mathrm{L}} / C_{0}$ 分别为 $1.80 、 1.88 、 1.94 ; \mathrm{TP} C_{\mathrm{L}} / C_{0}$ 值与 $\mathrm{TN}$ 相比差别并不大, 但在相同浓度下 $\left(C_{3}=10.0 \mathrm{mg} / \mathrm{L}\right) \mathrm{TP}$ 在冰体各层中的浓度比 $\mathrm{TN}$ 浓度小近 1 个数 量级,说明同浓度、同温度下结冰, TP 比 TN 更容易从冰体排出到冰下水体中.

$\mathrm{TP}$ 水样初始浓度 $\geqslant$ 地表水质标准 $\mathrm{V}$ 类标准限值 $(0.4 \mathrm{mg} / \mathrm{L})$ 时: 在 $-25 、-15^{\circ} \mathrm{C}$ 结冰, 冰体中 $\mathrm{TP}$ 浓度的 平均值均小于 II 类标准限值 $(0.1 \mathrm{mg} / \mathrm{L})$, 说明结冰对于湖泊水体中的 TP 也有净化作用. 2010 年的数据显 示, 乌梁素海冰封期冰体体积占总体积的 $1 / 3$ 到 $1 / 2$. 冰封期湖面形成较清洁的冰体, 而将 TN、TP 等营养盐 排人到冰下水体中, 使水体中的营养盐浓度增大, 对藻类及微生物的生长繁殖造成影响. 低温条件下, 湖水 复氧能力下降, 营养盐除了被微生物消耗外, 在浓度梯度的推动下还将打破其在水一沉积物之间的动态平 衡, 向底泥迁移.

乌梁素海 2011 年 1 月实测 $\mathrm{TN}$ 在冰体中的平均浓度为 $0.675 \mathrm{mg} / \mathrm{L}$, TP 在冰体中的平均浓度为 $0.198 \mathrm{mg} / \mathrm{L}^{[24]}$. 湖泊实测浓度均大于本模拟实验冰体中的 TN、TP 浓度, 尤其是 $\mathrm{TP}$ (图 2). 原因是湖水中物 质总浓度大导致排出效应减弱, 同时, 说明 TP 在冰水中的迁移过程与 TN 相比更容易受到系统其它因素的 影响.

$\mathrm{TP}$ 的 $K$ 值随浓度、温度的总体变化趋势与 TN 一致. ANOVA 分析可得: 结冰过程中, 初始 TP 水样浓度 为 $C_{1} 、 C_{2} 、 C_{3}$ 得到的 $K$ 值差异显著 $(P=0 、 0 、 0.011<0.05)$, 相同浓度下 $t$ 检验, 得出冻结温度为 $-25 、-15^{\circ} \mathrm{C}$ 时 TP 水样的 $K$ 值差异显著 $(P=0.001 、 0.012 、 0.023<0.05)$, 说明不同浓度、不同温度对 TP 浓度在冰-水中 
的分布的影响在统计学上有意义, 即冰封期 TP 浓度在冰一水介质中的迁移同样受到湖水中 TP 浓度和环境 温度的影响.

$2.1 .3 \mathrm{pH}$ 值对 $\mathrm{TN} 、 \mathrm{TP}$ 浓度在冰体一水体中分布的影响 $-25^{\circ} \mathrm{C}$ 条件下, TN、TP 浓度同为最小值 $\left(C_{1}\right)$ 和最大 值 $\left(C_{3}\right)$ 时, 中性、酸性、碱性水样结冰后得到冰柱各段中物质的浓度及 $K$ 值(图 3 ).

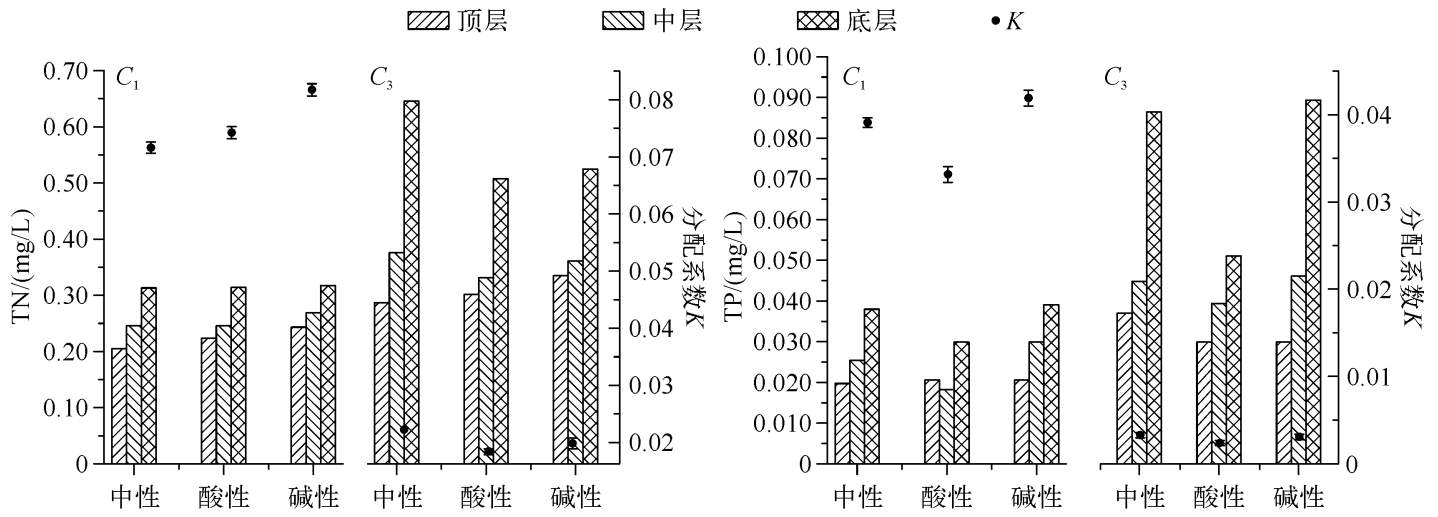

图 3 不同 $\mathrm{pH}$ 值下 $\mathrm{TN} 、 \mathrm{TP}$ 浓度在冰体-水体中的分布

Fig. 3 Distribution of TN and TP concentrations in the ice and water systems under different $\mathrm{pH}$ conditions

在不同的 $\mathrm{pH}$ 值条件下, 各物质在冰相中的浓度分布总体规律基本一致, 仍然是随溶液初始浓度的增大 而增加,且冰体各层浓度表现为顶层 $<$ 中层 <底层 ( 图 3 ).

运用单因素方差分析法 (ANOVA) 两两比较相同浓度、相同温度下, 不同 $\mathrm{pH}$ 值水样所得 $K$ 值的差异性. 浓度为 $C_{1}$ 时: 不同 $\mathrm{pH}$ 值条件下 TN $K$ 值的差异显著, $P$ 分别为 $0.046 、 0 、 0.000<0.05$; TP $K$ 值差异显著, $P$ 分别为 $0 、 0.010 、 0<0.05$. 浓度为 $C_{3}$ 时: TN 在酸、碱与中性条件下的 $K$ 值差异不显著, $P$ 分别为 0.970 、 $0.556>0.05$, 且酸、碱条件下 $K$ 值差异也不显著 $(P=0.435>0.05)$; TP 在中性、酸性条件下 $K$ 值差异性显 著, $P=0.002<0.05$, 在中性、碱性条件下 $K$ 值差异不显著, $P=0.287>0.05$, 且酸、碱条件下 $K$ 值差异显著, $P=0.011<0.05$.

结果表明: 在 $C_{1}$ 浓度下, $\mathrm{TN} 、 \mathrm{TP}$ 水样在结冰过程中由冰体向冰下水体的迁移受酸、碱度影响显著; 在 $C_{3}$ 浓度下, TN、TP 受 $\mathrm{pH}$ 值的影响不显著.

\section{2 浓度、温度、 $\mathrm{pH}$ 值对 $\mathrm{Na}^{+}$和 $\mathrm{Cl}^{-}$的影响}

实验共设置 4 个初始浓度 $\left(C_{1}<C_{2}<C_{3}<C_{4}\right)$ 对 $\mathrm{Na}^{+}$和 $\mathrm{Cl}^{-}$进行结冰模拟, 得出以下结论:

2.2.1 浓度、温度对 $\mathrm{Na}^{+}$和 $\mathrm{Cl}^{-}$在冰体一水体 中分布的影响 乌梁素海位于干旱半干旱地 区,降水和地表径流补给量少, 蒸发强度大, 总溶解性固体 (TDS) 较高是该区域湖泊主要 环境特征, 而组成 TDS 的主要成分是 $\mathrm{Na}^{+}$和 $\mathrm{Cl}^{-[25]}$. 模拟实验分别加人各浓度 $\mathrm{NaCl}$, 水溶 液中 $\mathrm{Na}^{+}$和 $\mathrm{Cl}^{-}$的浓度分别见表 2 .

不同浓度、不同温度下 $\mathrm{Na}^{+}$和 $\mathrm{Cl}^{-}$在冰 表 $2 \mathrm{NaCl}$ 初始溶液中 $\mathrm{Na}^{+}$和 $\mathrm{Cl}^{-}$的浓度

Tab. 2 Concentrations of $\mathrm{Na}^{+}$and $\mathrm{Cl}^{-}$in $\mathrm{NaCl}$ solution

\begin{tabular}{ccccc}
\hline & $C_{1} /(\mathrm{mg} / \mathrm{L})$ & $C_{2} /(\mathrm{mg} / \mathrm{L})$ & $C_{3} /(\mathrm{mg} / \mathrm{L})$ & $C_{4} /(\mathrm{mg} / \mathrm{L})$ \\
\hline $\mathrm{NaCl}$ & 250 & 1000 & 5000 & 10000 \\
$\mathrm{Na}^{+}$ & 97.4576 & 389.8305 & 1949.1525 & 3898.3051 \\
$\mathrm{Cl}^{-}$ & 152.5424 & 610.1695 & 3050.8475 & 6101.6949 \\
\hline
\end{tabular}
体中的分布及分配系数见图 4. 在同一温度下 结冰, 测得冰体中 $\mathrm{Na}^{+}$和 $\mathrm{Cl}^{-}$的浓度随离子初始浓度的增大而明显增加, 同一浓度下, 随结冰温度的升高, 冰 体各层的离子浓度都减小. 各层冰的浓度也表现为顶层 $<$ 中层 $<$ 底层.

用 $C_{\mathrm{L}} / C_{0}$ 表示冰下水体中离子浓度和结冰前水体离子浓度的比值, 浓度分别为 $C_{1} 、 C_{2} 、 C_{3} 、 C_{4}$ 时: $-25^{\circ} \mathrm{C}$ 结冰, $\mathrm{Na}^{+} C_{\mathrm{L}} / C_{0}$ 分别为 $1.94 、 1.63 、 1.55 、 1.57 ; \mathrm{Cl}^{-}$分别为 $1.95 、 1.59 、 1.50 、 1.53 .-15^{\circ} \mathrm{C}$ 结冰, $\mathrm{Na}^{+} C_{\mathrm{L}} / C_{0}$ 分 别为 $1.97 、 1.74 、 1.62 、 1.60 ; \mathrm{Cl}^{-}$分别为 $1.96 、 1.87 、 1.58 、 1.57$. 结冰使得湖泊冰下水体中 $\mathrm{Na}^{+}$和 $\mathrm{Cl}^{-}$增多, 


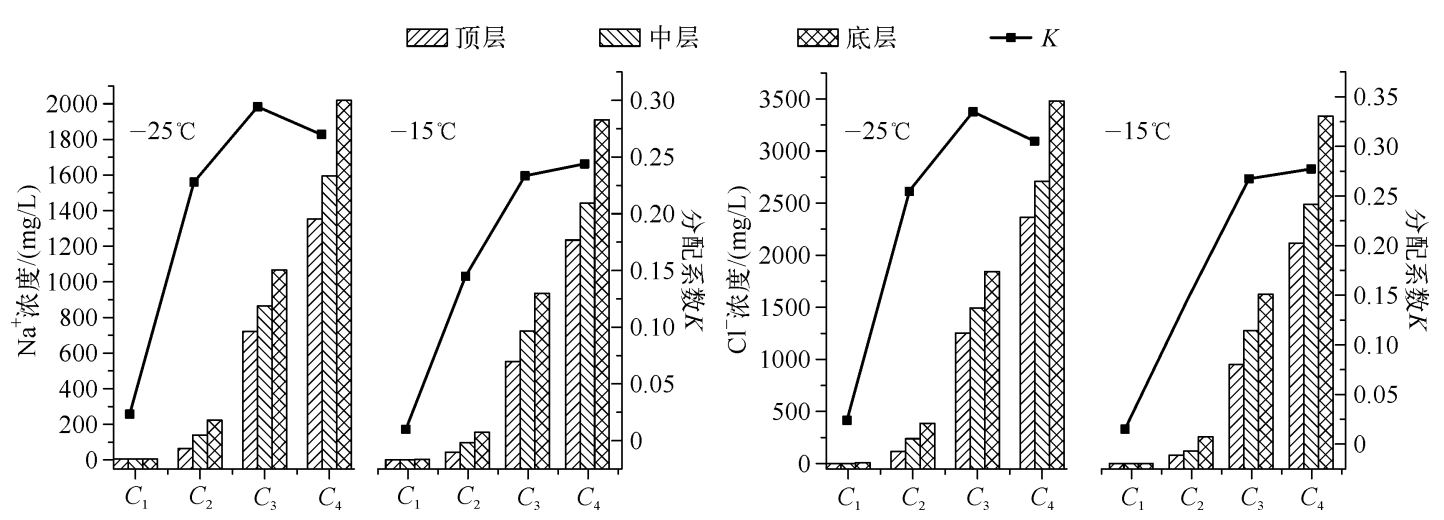

图 4 不同浓度、温度下 $\mathrm{Na}^{+} 、 \mathrm{Cl}^{-}$在冰体一水体中的分布

Fig. 4 Distribution of $\mathrm{Na}^{+}$and $\mathrm{Cl}^{-}$concentrations in the water and ice systems under different initial concentrations and freezing temperatures

通过与吸附在固体颗粒上的金属离子发生交换、配合, 可能引起沉积物中重金属的释放, 造成湖水中重金属 的二次污染.

结冰过程中, 随着溶液初始浓度的增加, TN、TP 及各离子由冰体向冰下水体的迁移量均减小. $\mathrm{Na}^{+}$和 $\mathrm{Cl}^{-}$的 $K$ 值变化趋势明显异于 $\mathrm{TN} 、 \mathrm{TP}$, 随初始溶液浓度的增加, 基本呈逐渐增大趋势 (图 4). 由于结冰过程 中冰体中 $\mathrm{Na}^{+}$和 $\mathrm{Cl}^{-}$浓度占整个冰一水体系的比例增大, 即 $C_{\mathrm{S}}$ 的增加量不再远低于 $C_{\mathrm{L}}$ 的增加量, 所以 $K$ 值随 $C_{\mathrm{S}}$ 的增加而增大. 盐度不同, 导致在相同的结冰时间所得冰体结构特征不同, 如图 1 , 高浓度 $\mathrm{NaCl}$ 结冰形成 冰柱较疏松而不通透, 使得离子由冰相到水相的排出能力减弱, $\mathrm{Na}^{+}$和 $\mathrm{Cl}^{-} K$ 值均大于 TN 、 TP 的 $K$ 值.

在相同条件下结冰, $\mathrm{Na}^{+}$和 $\mathrm{Cl}^{-}$的 $K$ 值变化趋势一致. 同一 $\mathrm{NaCl}$ 溶液中, $\mathrm{Cl}^{-}$的 $K$ 值略大于 $\mathrm{Na}^{+}$的 $K$ 值, 即 $\mathrm{Cl}^{-}$由冰体向冰下水体的迁移能力略强于 $\mathrm{Na}^{+}$. 运用单因素方差分析 (ANOVA) 分别得到: 结冰过程中, 原 水浓度为 $C_{1} 、 C_{2} 、 C_{3} 、 C_{4}$ 时 $\mathrm{Na}^{+}$和 $\mathrm{Cl}^{-}$水样的 $K$ 值差异显著 $\left(\mathrm{Na}^{+}: P=0 、 0 、 0 、 0 ; \mathrm{Cl}^{-}: P=0 、 0 、 0 、 0.022\right)$, 相同 浓度 $\left(C_{1} 、 C_{2} 、 C_{3} 、 C_{4}\right)$ 下分别运用独立样本 $t$ 检验, 分别得出冻结温度为 $-25 、-15^{\circ} \mathrm{C}$ 时 $\mathrm{Na}^{+}$和 $\mathrm{Cl}^{-}$水样的 $K$ 值差异显著 $\left(\mathrm{Na}^{+}: P=0 、 0 、 0 ; \mathrm{Cl}^{-}: P=0 、 0 、 0\right)$, 说明不同浓度、不同温度对 $\mathrm{Na}^{+}$和 $\mathrm{Cl}^{-}$浓度在冰体 - 水体中分 布的影响在统计学上有意义. 即冰封期湖泊中 $\mathrm{Na}^{+}$和 $\mathrm{Cl}^{-}$在冰一水介质中的迁移受湖水中离子初始浓度和环 境温度的影响.

2.2.2 $\mathrm{pH}$ 值对 $\mathrm{Na}^{+}$和 $\mathrm{Cl}^{-}$在冰体一水体中分布的影响 $\mathrm{Na}^{+}$和 $\mathrm{Cl}^{-}$浓度同为最小浓度 $\left(C_{1}\right)$ 时, 中性、酸性、碱 性水样结冰后得到冰柱各段中物质的浓度及 $K$ 值见图 5. 在不同的 $\mathrm{pH}$ 值条件下, $\mathrm{Na}^{+}$和 $\mathrm{Cl}^{-}$在冰相中的浓 度的分布随溶液初始浓度的增大而增加, 且冰体各层浓度表现为顶层 <中层 <底层.

运用单因素方差分析法 (ANOVA) 两两比较相同浓度、相同温度下,不同 $\mathrm{pH}$ 值水样所得 $K$ 值的差异性. 浓度为 $C_{1}$ 时: $\mathrm{Na}^{+}$中性水样与酸、碱性水样的 $K$ 值差异显著, $P$ 分别为 $0 、 0.000<0.05$, 但酸性条件与碱性条 件下 $K$ 值差异不显著 $(P=0.633) ; \mathrm{Cl}^{-} K$ 值的差异显著, $P$ 分别为 $0 、 0.000 、 0.002<0.05$. 浓度为 $C_{4}$ 时: 酸、 碱与中性条件下 $\mathrm{Na}^{+}$(或 $\mathrm{Cl}^{-}$) $K$ 值的差异性均显著.

结果表明: 与 $\mathrm{TN} 、 \mathrm{TP}$ 不同, 在 $C_{1}$ 和 $C_{4}$ 浓度下, $\mathrm{Na}^{+} 、 \mathrm{Cl}^{-}$水样在结冰过程中由冰体向冰下水体的迁移受 酸、碱度影响均显著.

\section{3 结论}

对 TN、TP 和 $\mathrm{NaCl}$ 水样在不同浓度、温度、pH 值条件下的单向结冰进行模拟,得出以下结论:

1) 结冰具有排出物质的作用. 水样中 $\mathrm{TN} 、 \mathrm{TP} 、 \mathrm{Na}^{+}$和 $\mathrm{Cl}^{-}$在结冰过程中不断从冰相向冰下水相迁移, 各 物质在冰体中的浓度均小于原水样中的浓度, 即结冰有净化湖泊水体的作用.

2) $\mathrm{TN} 、 \mathrm{TP} 、 \mathrm{Na}^{+}$和 $\mathrm{Cl}^{-}$在冰相各层中的浓度分布均表现为: 顶层 < 中层 <底层. 水样初始浓度增加, 结冰 


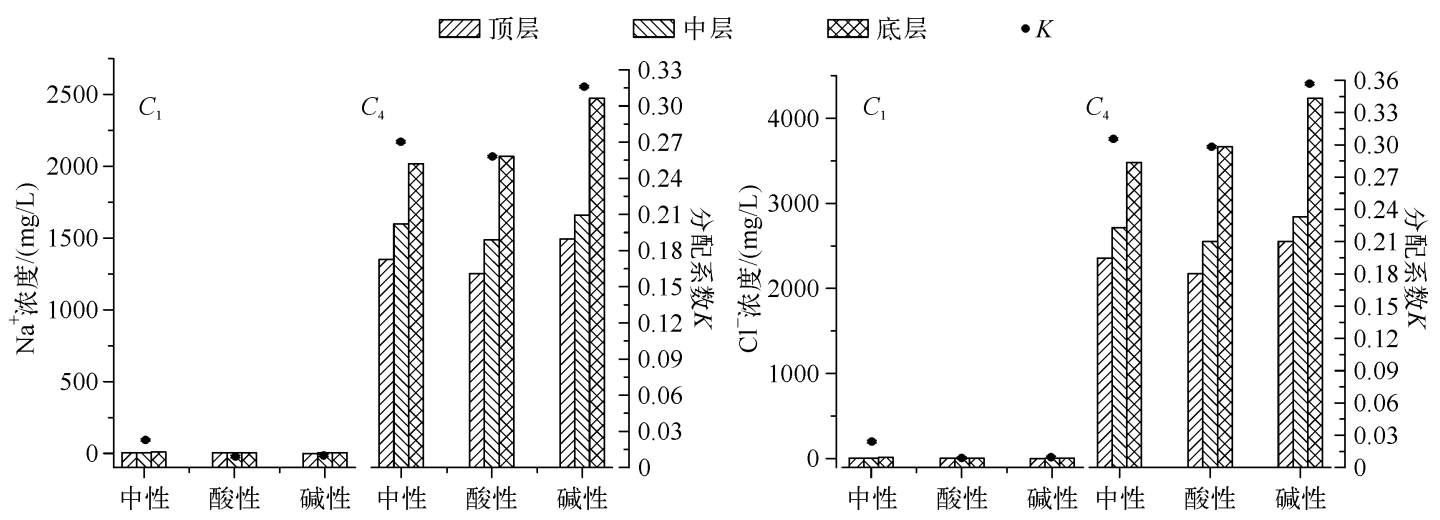

图 5 不同 $\mathrm{pH}$ 值下 $\mathrm{Na}^{+}$和 $\mathrm{Cl}^{-}$在冰体-水体中的分布

Fig. 5 Distribution of $\mathrm{Na}^{+}$and $\mathrm{Cl}^{-}$concentrations in the ice and water systems under different $\mathrm{pH}$ conditions 对物质的排出作用减弱, 留在冰相中的物质浓度增大; 温度相对升高, 结冰对物质的排出作用增大, 留在冰 相中的物质浓度减小; $\mathrm{Na}^{+} 、 \mathrm{Cl}^{-}$在冰体中的浓度受初始水样浓度的影响大于 TN、TP.

3 ) 不同物质由于自身性质不同测得 $K$ 值不同. 随初始浓度的增大, TN 、 TP 留在冰体中的浓度增加量远 小于冰下水体的增加量, 使得 $K$ 值呈下降趋势, 而 $\mathrm{Na}^{+}$和 $\mathrm{Cl}^{-}$随浓度的增加呈上升趋势; 同浓度下, 各物质水 样随结冰温度升高, $K$ 值均减小.

4) 假设检验的显著性水平 $\alpha$ 为 0.05 时:不同浓度、不同温度下各物质的分配系数 $K$ 值的差异均显著, 即 $\mathrm{TN} 、 \mathrm{TP} 、 \mathrm{Na}^{+}$和 $\mathrm{Cl}^{-}$的初始浓度、结冰温度显著影响其在冰水中的分布; 不同 $\mathrm{pH}$ 值条件下, 各物质的低初 始浓度水样 $K$ 值差异显著, TN TP 高初始浓度下 $K$ 值的差异不显著, $\mathrm{Na}^{+}$和 $\mathrm{Cl}^{-}$高初始浓度下的 $K$ 值差异显 著, 即当 $\mathrm{TN} 、 \mathrm{TP} 、 \mathrm{Na}^{+}$和 $\mathrm{Cl}^{-}$初始浓度为地表水环境质量标准中 $\mathrm{V}$ 类水标准限值 $\left(C_{1}\right)$ 时, 水体 $\mathrm{pH}$ 值显著影 响其在冰体一水体中的分布, 但当初始浓度增加至 $C_{1}$ 的 $5 \sim 40$ 倍时, 水体 $\mathrm{pH}$ 值对 $\mathrm{Na}^{+}$和 $\mathrm{Cl}^{-}$的分布影响显 著, 对 TN、TP 的影响不显著.

5 ) 冰封期湖泊中不同物质表现出不同的分布特征, 物质在冰一水介质中的迁移受到物质初始浓度、温度 和湖水 $\mathrm{pH}$ 值等环境因素的影响. 结冰过程中冰下水体污染物的增多不仅对水生生态系统造成影响, 还可能 会打破物质在沉积物与水体间的动态平衡, 促使污染物的沉积或释放. 然而, 天然湖泊是一个复杂的生态系 统, 冰封期物质的迁移过程对相关生物地球化学循环的影响仍需要进一步的深人研究和探讨.

\section{4 参考文献}

[ 1 ] Moreno FL, Raventós M, Hernández E et al. Freeze-concentration of coffee extract: Effect of freezing and thawing stages on solute recovery and bioactive compounds. Journal of Food Engineering, 2014, 120 : 158-166.

[ 2 ] Gao W, Habib M, Smith D. Removal of organic contaminants and toxicity from industrial effluents using freezing processes. Desalination, 2009, 245: 108-119.

[ 3 ] Kammerer P, Lee G. Freeze concentration of organic compounds in dilute aqueous solutions. Water Research, 1969,(3): 276-278.

[ 4 ] Himes R, Miller S, Mink W. Zone freezing in demineralizing saline waters. Industrial \& Engineering Chemistry Research, 1959, $51: 1345-1348$.

[ 5 ] Lorain O, Thiebaud P, Badorc E et al. Potential of freezing in wastewater treatment: soluble pollutant applications. Water Research, 2001, $35: 1137-1143$.

[ 6 ] Gay G, Lorain O, Azouni A et al. Wastewater treatment by radial freezing with stirring effects. Water Research, 2003 , 37 : 2520-2524.

[ 7 ] 李向应, 李忠勤, 陈正华等. 天山乌鲁木齐河源 1 号冰川雪坑中 $\mathrm{pH}$ 值和电导率的季节变化及淋溶过程. 地球科学 进展, 2006,21 (5):487-495. 
[ 8 ] 于 涛,马 军. 冷冻分离- RO 工艺处理空间站尿液试验研究. 哈尔滨工业大学学报,2006,38(4):567-584.

[ 9 ] 张 岩, 李畅游, 张 生等. 呼伦湖冰封期污染特征分析及对水处理的意义. 生态环境学报, 2011, 20 (8/9): 1289-1294.

[10] 张晓庆, 许印军, 顾卫等. 环渤海盐碱地区模拟生活污水冷冻处理试验. 环境科学研究, 2012,25(9): 1030-1034.

[11] 李志军,王 昕, 李青山等. 不同条件下硝基苯在水-冰体系中的分配研究. 中国科学: $\mathrm{E}$ 辑: 技术科学, 2008,38 (7) : 1131-1138.

[12] 吴 攀, 邓建明,秦伯强等. 水温和营养盐增加对太湖冬、春季节藻类生长的影响. 环境科学研究, 2013,26(10): 1064-1071.

[13] 黄继国,傅金廷,王雪松等. 湖水冰封期营养盐及浮游植物的分布特征. 环境科学学报,2009,29(8):1678-1683.

[14] 黄继国,彭祥捷,俞 双等. 水体结冰期营养盐和叶绿素 $\mathrm{a}$ 的分布特征. 吉林大学学报,2008,46(6):1231-2135.

[15］崔凤丽,李畅游, 史小红等.乌梁素海主要离子季节变化特征分析. 干旱区资源与环境,2013,27(8):317-342.

[16] 赵胜男,史小红, 李畅游等. 乌梁素海水体永的分布特征及污染风险评估. 湖泊科学, 2014,26(2):221-227. DOI 10. $18307 / 2014.0208$.

[17] 李卫平,徐 静, 于玲红等. 乌梁素海冰封期营养盐及浮游植物的分布特征. 生态环境学报, 2014, 23 (6): 1007-1013.

[18］姜慧琴. 乌梁素海营养盐在冰体中的空间分布及其在冻融过程中释放规律的试验研究 [学位论文]. 呼和浩特: 内 蒙古农业大学,2011.

[19] 国家环境保护总局《水和废水监测分析方法》编委会. 水和废水监测分析方法: 第 4 版. 北京: 中国环境科学出版 社, 2002 .

[20] Yu T, Ma JZ, Li Q. Factors affecting ice crystal purity during freeze concentration process for urine treatment. Journal of Harbin Institute of Technology, 2007, 14(5) : 593-597.

[21] Luo CS, Chen WW, Han WF. Experimental study on factors affecting the quality of ice crystal during the freezing concentration for the brackish water. Desalination, 2010, 260: 231-238.

[22] 张 岩, 李畅游, SHEN Hungtao 等. 乌梁素海湖泊冰生长过程中总氮的迁移规律. 水科学进展, 2013, 24 (5): 728-735.

[23] Akyurt M, Zaki G, Haeebullah B. Freezing phenomena in ice-water systems. Energy Conversion and Management, 2002 (43) : 1773-1789.

[24] 于 涛, 马 军. 冷冻浓缩水处理工艺中冰晶纯度影响因素分析. 哈尔滨商业大学学报: 自然科学版, 2005,21 (5): 572-578.

[25] 张 岩. 乌梁素海结冰过程中污染物迁移机理及其应用研究 [学位论文]. 呼和浩特: 内蒙古农业大学, 2012 . 